\title{
Risk Factor Profile and Quality of Life of Psoriasis Vulgaris
}

\author{
As'ad Naufal $^{1}$, Damayanti ${ }^{2}$, Etty Hary Kusumastuti ${ }^{3}$, Afif Nurul Hidayati \\ ${ }^{1}$ Faculty of Medicine, Universitas Airlangga, Surabaya, Indonesia \\ ${ }^{2}$ Department of Dermatology and Venereology, Faculty of Medicine, Universitas Airlangga/Dr. Soe- \\ tomo General Academic Hospital Surabaya, Indonesia \\ ${ }^{3}$ Department of Anatomic Pathology, Faculty of Medicine, Universitas Airlangga/Dr. Soetomo Gen- \\ eral Academic Hospital Surabaya, Indonesia
}

\begin{abstract}
Background: Psoriasis is an autoimmune human skin disease. It is a chronic and recurrent lesion characterized by erythema patches with well-defined borders with rough, multi-layered, and transparent scales with a significant negative impact on patients' quality of life. Several risk factors for psoriasis can decrease patient' quality of life. Purpose: To determine the risk factor profile and quality of life of psoriasis patients at the dermatology and venereology outpatient clinic at Dr. Soetomo General Academic Hospital Surabaya. Methods: This was a cross-sectional study involving new and control psoriasis patients. Their risk factors were evaluated using questionnaires, and their quality of life was measured using the DLQI questionnaires. The data was collected at the Dermatology and Venereology outpatient unit Dr. Soetomo General Academic Hospital Surabaya. Result: Of the 24 patients, the biggest risk factor for psoriasis patients was trauma/ Koebner phenomenon, as reported in 15 patients (62.5\%), and 11 patients' (45.8\%) quality of life was affected. Conclusion: Trauma was the largest risk factor for psoriasis, and psoriasis has significantly affected patient' quality of life.
\end{abstract}

Keywords: psoriasis, quality of life, risk factor, human and disease

Correspondence: Damayanti, Department of Dermatology and Venereology Faculty of Medicine, Universitas Airlangga/ Dr. Soetomo General Academic Hospital, Surabaya, J1. Mayjen Prof. Dr. Moestopo No 6-8, Surabaya, 60132, Indonesia. Phone: (031) 5501078, email: damayanti@fk.unair.ac.id.

\section{BACKGROUND}

Psoriasis is a chronic autoimmune human skin disease. It is chronic and recurrent in nature, which is characterized by the presence of well-defined erythema patches with a rough, multi-layered, and transparent scale, accompanied by the phenomenon of candle grease, Auspitz and Koebner signs. Psoriasis is influenced by genetic factors, causing epidermal growth and differentiation, and multiple biochemical, immunological, and vascular abnormalities. ${ }^{1,2}$

Psoriasis can adversely impact patient's quality of life. Psoriasis can occur at any age, but mostly in the 50-69 age group. The prevalence of psoriasis is reported in various countries between $0.09 \%$ and $11.4 \%$, making psoriasis a serious global problem. ${ }^{3}$ From January $1^{\text {st }}, 2016$ to December $31^{\text {st }}, 2017$, there were 36 psoriasis vulgaris patients at the Inpatients Installation Kemuning I and II Dermatology and Venereology Outpatients Unit Dr. Soetomo General Academic Hospital Surabaya. ${ }^{4}$

Risk factors that cause psoriasis include trauma/Koebner phenomenon, sunlight, cigarettes, alcohol, drug consumption, infection. ${ }^{5}$ Lewis and Finlay reported that DLQI is the most widely used questionnaire in the field of dermatology and studies of patients with skin diseases. The Dermatology Life Qual- ity Index consists of ten questions regarding symptoms and feelings, daily activities, leisure, work and school, personal relationships, and therapy. ${ }^{6}$ Therefore, psoriasis can occur unexpectedly, and research on the risk factor for psoriasis and the quality of life of psoriasis disease still lacks, especially in Surabaya. This research is expected to provide additional information related to risk factors for psoriasis related to the quality of life and further reduce the incidence of psoriasis.

\section{METHODS}

This was a cross-sectional study. The sample population was all psoriasis patients at the Dr. Soetomo General Academic Hospital Surabaya admitted from December 2019 to February 2020. The sample size was 24, and it was in line with the Slovin's formula. $^{7}$

Sampling was done using consecutive sampling. The research variables were risk factors and quality of life. The data were collected and grouped based on the research variables and arranged in a frequency distribution table. The data were analyzed using descriptive methods to evaluate risk factors and quality of life. 
This research has been reviewed and approved by the Ethics Committee of Dr. Soetomo General Academic Hospital Surabaya (1672/KEPK/XI/2019).

\section{RESULT}

This study involved 24 patients who have met the inclusion criteria. The study variables were the risk factors and the quality of life for psoriasis.

Table 1. Distribution of Subjects

\begin{tabular}{llrr}
\hline & Category & Frequency & Percent (\%) \\
\hline \multirow{2}{*}{ Sex } & Male & 13 & 54.2 \\
& Female & 11 & 45.8 \\
\cline { 2 - 4 } & Total & 24 & 100 \\
\hline \multirow{2}{*}{ Age } & $\begin{array}{l}\text { Teenager }(11- \\
24 \text { years }) \\
\text { Adult }(25- \\
44 \text { years }) \\
\text { Elderly }(\geq 45 \\
\text { years })\end{array}$ & 4 & 16.7 \\
\cline { 2 - 3 } & 5 & 20.8 \\
Total & 15 & 62.5 \\
\hline
\end{tabular}

Table 1 shows 13 male psoriasis patients $(54.2 \%)$ and 11 female psoriasis patients $(45.8 \%)$. There were 4 patients $(16.7 \%)$ in the $11-24$ years age group, followed by 5 patients $(20.8 \%)$ in 25-44 years, and 15 patients $(62.5 \%)$ in $\geq 45$ years age group.

Nine patients $(37.5 \%)$ had no trauma (friction/pressure), and 15 patients $(62.5 \%)$ had trauma (friction/pressure). Also, 18 patients $(75 \%)$ had outdoor jobs, and 6 patients $(25 \%)$ had indoor jobs. Fourteen patients $(58.3 \%)$ stayed outdoor for $\leq 1$ hour per day, 5 patients $(20.8 \%)$ stayed outdoor for $2-3$ hours per day, 1 patient $(4.2 \%)$ stayed outdoor for $3-$ hours per day, and 4 patients $(16.7 \%)$ stayed outdoor for $>5$ hours per day.

Eleven patients $(45.8 \%)$ did not use any protection when they were outdoor, and 13 patients $(54.2 \%)$ used protection, such as an umbrella, hat, or sunscreen, when they were outside. Fourteen patients $(58.3 \%)$ were smokers, and 10 patients $(41.7 \%)$ were not smokers. One patient $(10 \%)$ has smoked for $\leq 2$ years, 3 patients $(30 \%)$ have smoked for 3-5 years, and 6 patients $(60 \%)$ have smoked for $>10$ years. Seven patients (70\%) smoked 1-5 cigarettes per day, 1 patient (10\%) smoked 6-10 cigarettes per day, 1 patient (10\%) smoked 1 pack per day, and 1 patient $(10 \%)$ smoked $>2$ packs per day.
Fifteen patients $(62.5 \%)$ were not alcohol consumers, 9 patients $(37.5 \%)$ were alcohol consumers. Two patients $(22.2 \%)$ have been drinking alcoholic beverages for $\leq 2$ years, 4 patients $(44.5 \%)$ have been drinking for $3-5$ years, 1 patient $(11.1 \%)$ has been drinking for 6-10 years, and 2 patients $(22.2 \%)$ has been drinking for $>10$ years. Eight patients $(88.9 \%)$ consumed alcohol as much as $\leq 2$ bottles per week, and 1 patient $(11.1 \%)$ consumed $>10$ bottles per week.

Thirteen patients $(54.2 \%)$ were not coughing and cold since affected by psoriasis, and 11 (45.8\%) were coughing and cold for 4 weeks since affected by psoriasis. Nine patients $(37.5 \%)$ reported no tooth pain since affected by psoriasis, and 15 patients $(62.5 \%)$ reported tooth pain since affected by psoriasis. Six female patients (54.5\%) had vaginal discharge since affected by psoriasis, and 5 female patients (45.5\%) did not have vaginal discharge since affected by psoriasis. All patients $(100 \%)$ did not take drugs containing lithium, antimalarials, inderal, quinidine, and indomethacin.

All patients were successfully studied for their quality of life on how much psoriasis has affected their life within a week using the Dermatology Life Quality Index questionnaire. This questionnaire consists of ten questions about symptoms and feelings, daily activities, leisure activities, work and school, personal relationships, and therapy. The symptom and feeling aspects consist of two questions (number 1 and 2). The aspect of daily activities consists of two questions (number 3 and 4). The aspect of activities in spare time consists of two questions (number 5 and $6)$. The aspect of work and school only consists of one question (number 7). The personal relationship aspect consists of two questions (number 8 and 9), and the therapeutic aspect consists of one question (number 10).

Each number has 0-3 scored. A higher score indicates a poorer quality of life. Here are the results of the score indicator from the Dermatology Life Quality Index questionnaire.

Table 3 shows that in the aspects of the symptoms and feelings, 4 patients $(16.7 \%)$ scored 2,2 patients $(8.3 \%)$ scored 3, 6 patients $(33.3 \%)$ scored 4,4 patients $(25 \%)$ scored 5 , and 8 patients $(33.3 \%)$ scored 6 . In the aspects of daily activities, 6 patients (25\%) scored 0, 4 patients (16.7\%) scored 2, 1 patient (4.2\%) scored 3, 5 patients $(20.8 \%)$ scored 4, 3 patients $(12.5 \%)$ scored 5 , and 5 patients $(20.8 \%)$ scored 6. 
Table 2. Risk Factor of Psoriasis

\begin{tabular}{|c|c|c|c|}
\hline Parameter & Category & Frequency & Percent $(\%)$ \\
\hline \multirow{3}{*}{$\begin{array}{l}\text { Koebner } \\
\text { phenomenon }\end{array}$} & Not & 9 & 37.5 \\
\hline & Yes & 15 & 62.5 \\
\hline & Total & 24 & 100 \\
\hline \multirow{3}{*}{$\begin{array}{l}\text { Outdoor } \\
\text { work }\end{array}$} & Not & 18 & 75 \\
\hline & Yes & 6 & 25 \\
\hline & Total & 24 & 100 \\
\hline \multirow{5}{*}{$\begin{array}{l}\text { Length of } \\
\text { stay outdoors } \\
\text { per day }\end{array}$} & $\leq 1$ hour & 14 & 58.3 \\
\hline & $2-3$ hours & 5 & 20.8 \\
\hline & $3-5$ hours & 1 & 4,2 \\
\hline & $>5$ hours & 4 & 16.7 \\
\hline & Total & 24 & 100 \\
\hline \multirow{3}{*}{$\begin{array}{l}\text { Outdoor } \\
\text { Protection }\end{array}$} & Not & 11 & 45.8 \\
\hline & Yes & 13 & 54.2 \\
\hline & Total & 24 & 100 \\
\hline \multirow{3}{*}{ Smoke } & Not & 14 & 58.3 \\
\hline & Yes & 10 & 41.7 \\
\hline & Total & 24 & 100 \\
\hline \multirow{4}{*}{$\begin{array}{l}\text { How long to } \\
\text { smoke }\end{array}$} & $\leq 2$ years & 1 & 10 \\
\hline & $3-5$ years old & 3 & 30 \\
\hline & $>10$ years & 6 & 60 \\
\hline & Total & 10 & 100 \\
\hline \multirow{5}{*}{$\begin{array}{l}\text { Consumption } \\
\text { of cigarettes } \\
\text { in a day }\end{array}$} & $1-5$ sticks & 7 & 70 \\
\hline & 6-10 sticks & 1 & 10 \\
\hline & 1 pack & 1 & 10 \\
\hline & $>2$ packs & 1 & 10 \\
\hline & Total & 10 & 100 \\
\hline \multirow{3}{*}{$\begin{array}{l}\text { Consumption } \\
\text { of alcohol }\end{array}$} & Not & 15 & 62.5 \\
\hline & Yes & 9 & 37.5 \\
\hline & Total & 24 & 100 \\
\hline \multirow{5}{*}{$\begin{array}{l}\text { Duration of } \\
\text { consuming } \\
\text { alcohol }\end{array}$} & $\leq 2$ years & 2 & 22.2 \\
\hline & 35 years old & 4 & 44.5 \\
\hline & $6-10$ years & 1 & 11.1 \\
\hline & $>10$ years & 2 & 22.2 \\
\hline & Total & 9 & 100 \\
\hline \multirow{3}{*}{$\begin{array}{l}\text { Weekly al- } \\
\text { cohol con- } \\
\text { sumption }\end{array}$} & $\leq 2$ bottles & 8 & 88.9 \\
\hline & $>10$ bottles & 1 & 11.1 \\
\hline & Total & 9 & 100 \\
\hline \multirow{3}{*}{$\begin{array}{l}\text { Cold cough } \\
\text { frequency } \\
\text { rate }\end{array}$} & Not & 13 & 54.2 \\
\hline & Yes & 11 & 45.8 \\
\hline & Total & 24 & 100 \\
\hline \multirow{3}{*}{ Tooth pain } & Not & 9 & 37.5 \\
\hline & Yes & 15 & 62.5 \\
\hline & Total & 24 & 100 \\
\hline \multirow{3}{*}{$\begin{array}{l}\text { Vaginal } \\
\text { discharge }\end{array}$} & Not & 6 & 54.5 \\
\hline & Yes & 5 & 45.5 \\
\hline & Total & 11 & 100 \\
\hline \multirow{7}{*}{$\begin{array}{l}\text { Take medi- } \\
\text { cine }\end{array}$} & Irrelevant & 24 & 100 \\
\hline & Lithium & 0 & 0 \\
\hline & Antimalarial & 0 & 0 \\
\hline & Inderal & 0 & 0 \\
\hline & Quinidine & 0 & 0 \\
\hline & Indomethacin & 0 & 0 \\
\hline & Total & 24 & 100 \\
\hline
\end{tabular}

Table 3. DLQI score

\begin{tabular}{|c|c|c|c|}
\hline & Score & Frequency & Percent (\%) \\
\hline \multirow{8}{*}{$\begin{array}{l}\text { Symptoms } \\
\text { and feeling }\end{array}$} & 0 & 0 & 0 \\
\hline & 1 & 0 & 0 \\
\hline & 2 & 4 & 16.7 \\
\hline & 3 & 2 & 8.3 \\
\hline & 4 & 6 & 25 \\
\hline & 5 & 4 & 16.7 \\
\hline & 6 & 8 & 33.3 \\
\hline & Total & 24 & 100 \\
\hline \multirow{8}{*}{$\begin{array}{c}\text { Daily } \\
\text { activities }\end{array}$} & 0 & 6 & 25 \\
\hline & 1 & 0 & 0 \\
\hline & 2 & 4 & 16.7 \\
\hline & 3 & 1 & 4.2 \\
\hline & 4 & 5 & 20.8 \\
\hline & 5 & 3 & 12.5 \\
\hline & 6 & 5 & 20.8 \\
\hline & Total & 24 & 100 \\
\hline \multirow{8}{*}{ Leisure } & 0 & 5 & 20.8 \\
\hline & 1 & 5 & 20.8 \\
\hline & 2 & 6 & 25 \\
\hline & 3 & 3 & 12.5 \\
\hline & 4 & 1 & 4.2 \\
\hline & 5 & 2 & 8.3 \\
\hline & 6 & 2 & 8.3 \\
\hline & Total & 24 & 100 \\
\hline \multirow{8}{*}{$\begin{array}{c}\text { Work and } \\
\text { school }\end{array}$} & 0 & 13 & 54.2 \\
\hline & 1 & 5 & 20.8 \\
\hline & 2 & 0 & 0 \\
\hline & 3 & 6 & 25 \\
\hline & 4 & 0 & 0 \\
\hline & 5 & 0 & 0 \\
\hline & 6 & 0 & 0 \\
\hline & Total & 24 & 100 \\
\hline \multirow{8}{*}{$\begin{array}{l}\text { Personal } \\
\text { relationship }\end{array}$} & 0 & 14 & 58.3 \\
\hline & 1 & 4 & 16.7 \\
\hline & 2 & 2 & 8.3 \\
\hline & 3 & 2 & 8.3 \\
\hline & 4 & 1 & 4.2 \\
\hline & 5 & 0 & 0 \\
\hline & 6 & 1 & 4.2 \\
\hline & Total & 24 & 100 \\
\hline \multirow{8}{*}{ Treatment } & 0 & 11 & 45.8 \\
\hline & 1 & 5 & 20.8 \\
\hline & 2 & 4 & 16.7 \\
\hline & 3 & 4 & 16.7 \\
\hline & 4 & 0 & 0 \\
\hline & 5 & 0 & 0 \\
\hline & 6 & 0 & 0 \\
\hline & Total & 24 & 100 \\
\hline
\end{tabular}

DLQI: Dermatology life quality index 
Table 4. Interpretation of DLQI Scores

\begin{tabular}{clrr}
\hline & Category & Frequency & Percent (\%) \\
\hline & Small & 2 & 8.3 \\
& Moderate & 7 & 29.2 \\
Interpreta- & Very & 11 & 45.8 \\
tion of DLQI & large & & \\
Scores & Extremely & 4 & 16.7 \\
& large & & 100 \\
\cline { 2 - 4 } & Total & 24 & \\
\hline
\end{tabular}

DLQI: Dermatology life quality index

In the aspects of activities in leisure time, 5 patients $(20.8 \%)$ scored 0,5 patients $(20.8 \%)$ scored 1,6 patients $(25 \%)$ scored 2, 3 patients $(12.5 \%)$ scored 3, 1 patient $(4.2 \%)$ scored 4,2 patients $(8.3 \%)$ scored 5 , and 2 patients $(8.3 \%)$ scored 6 . In the aspects of work and school, 13 patients $(54.2 \%)$ scored 0,5 patients $(20.8 \%)$ scored 1 , and 6 patients $(25 \%)$ scored 3 . In the aspects of personal relationships, 14 patients (58.3\%) scored 0, 4 patients (16.7\%) scored 1, 2 patients $(8.3 \%)$ scored 2, 2 patients $(8.3 \%)$ scored 3, 1 patient (4.2\%) scored 4, and 1 patient (4.2\%) scored 6. In aspects of therapy, 11 patients $(45.8 \%)$ scored 0 , 5 patients (20.8\%) scored 1, 4 patients (16.7\%) scored 2 , and 4 patients (16.7\%) sored 3 .

Table 4 shows that psoriasis mildly affected 2 patients (8.3\%), moderately affected 7 patients (29.2\%), significantly affected 11 patients $(45.8 \%)$, and extremely affected 4 patients $(16.7 \%)$.

\section{DISCUSSION}

This study involved 24 individuals with psoriasis. This study covers the risk factor data (Koebner phenomenon, outdoor work, cigarettes, alcohol, cold cough, tooth pain, vaginal discharge, allergies) and quality of life data assessed by the dermatology life quality index questionnaire.

We found that most psoriasis patients were males, as many as 13 patients. Psoriasis is not genderspecific. Studies on routine clinical measurement of symptoms reported no difference in the severity of physical symptoms between males and females. ${ }^{8}$ Most psoriasis patients were in the range of $46-65$ years age group, as many as 13 patients. DisabilityAdjusted Life Year (DALY) increases as one reaches 60 years old or older, and this applies to both males and females. Research showed that the most burden of disease occurs in the 50-69 years age group. ${ }^{3}$ In this study, $62.5 \%$ of patients (15 patients) of psoriasis were mostly found in elderly patients ( $>45$ years old), $20.8 \%$ adults (25-44 years old) and the last was $16.7 \%$ teenagers (11-24 years old). This is comparable with previous studies, which stated that the most common age in psoriasis patients was $45-65$ years old. There is no specific classification of age groups in this study, because the research subjects were taken from adult patients from the Allergy Division, at the Dermatology and Venereology outpatient unit Dr. Soetomo General Academic Hospital Surabaya.

Most psoriasis patients experienced Koebner's phenomenon, as observed in 15 patients $(62.5 \%)$, in which psoriasis lesions were known to appear in areas of trauma and body areas that are often scratched or subjected to friction, according to research conducted in 2013 by Camargo et al. after ten scratches made at the same time, the psoriasis lesions did not appear in all areas simultaneously but gradually over the next days, indicating that lesion response time varies. In general, the time interval for koebnerization is $10-20$ days. $^{9}$

In this study, most psoriasis patients, which was 18 patients $(75 \%)$, worked indoors. We found that those psoriasis patients are mostly going outdoor for less than 1 hour per day. We also found that 13 patients $(54.2 \%)$ wear protection when outdoor. Sun exposure is generally beneficial, but in $5-20 \%$ of psoriasis patients, it can cause psoriasis and summer exacerbations on exposed skin. In 2013, Balato et al. reported a significant impact of sun introduction and conceivable photo-induced decline in some cases. In psoriasis arthritis, patients are affected by humidity, warmer, and colder temperature. Lower humidity increments skin permeability, and this induces the thickening of the epidermis, and stimulating the generation of inflammatory mediators; therefore, worsening psoriasis. In higher humidity, instep, it unfavorably influences joint conditions. ${ }^{10}$

Ten patients (41\%) with psoriasis were smokers, 6 of them $(60 \%)$ have smoking for more than 10 years, 7 of them $(70 \%)$ smoked $1-5$ cigarettes per day. Smoking is found to be an autonomous chance for psoriasis in both sexes. Psoriasis progresses faster in individuals with longer smoking. ${ }^{11}$ This suggests that smoking can contribute to the chronic nature of psoriasis.

Psoriasis is mediated by Th1 and Th17 helper T cells. Smoking produces free radicals, which will enact as signaling pathways in psoriasis, such as the mitogen-activated kinase, nuclear factor $\kappa \mathrm{B}$, and Janus kinase-STAT pathways. Byproducts from smoking, such as nicotine and dioxin, actuate $\mathrm{T}$ cells that deliver interleukin 12 (IL-12), IL-17, and IL-22. ${ }^{6}$ Since IL-17 is one of the major cytokines included within the pathogenesis of psoriasis, there are mechanistic reasons to accept that smoking seem to contribute to the improvement of psoriasis. ${ }^{12}$ 
Nine patients $(37.5 \%)$ did not consume alcohol, 9 patients have consumed alcohol for 3-5 years, and 4 patients $(44.5 \%)$ consumed 2 bottles per week. Psoriasis patients with excessive alcohol consumption tend to have more severe inflammation. Alcohol can affect psoriasis through several mechanisms, such as increased susceptibility to infection, stimulation proliferation of lymphocytes and keratinocytes, and the production of proinflammatory cytokines. ${ }^{12}$ The research subjects identify themselves as social alcoholics. This means that they consume alcoholic beverages mainly for social purposes.

A study conducted by 36 subjects showed that 20 of 36 guttate psoriasis patients had a history of upper respiratory tract infection. ${ }^{14}$

The majority of patients reported that they had tooth pain. This is in line with the study conducted by Dalmady et al. in 2019. Periodontal infection may be considered a common comorbid condition in psoriasis. Psoriasis and periodontal disease share a few standard immunologic, microbiological and natural pathogenetic components. ${ }^{15}$ In 2020 , Yu Su et al. also found that the incidence rate of periodontitis was higher in patients with psoriasis arthritis. ${ }^{16}$ Duarte et al. in 2010 suggest that the immune response caused by psoriasis can make a patient susceptible to the development of chronic odontitis and vice versa. ${ }^{17}$

A smaller number of female psoriasis patients experienced vaginal discharge. A common infectious cause of vaginal discharge that affects about $75 \%$ of women at some time during their reproductive years is vulvovaginal candidiasis. ${ }^{18}$ However, research reported that Candida infection in psoriasis patients usually does not worsen the psoriasis itself. ${ }^{19}$

None of psoriasis patients taking drugs containing lithium, anti malarial, inderal, quinidine, and indomethacin. In 2016, Burden et al. stated that drugs that can worsen psoriasis in current clinical practice are lithium salt and synthetic antimalarials. ${ }^{5}$

The most patients were affected by psoriasis significantly. This is in line with research by Kowalewska et al. in 2020. They reported that patients with psoriasis appeared to have direct levels of illness acceptance and stigmatization, lower quality of life, and decently deteriorated quality of life. Acceptance of illness was considerably modulated by patient sex. The level acceptance of illness among men was significantly higher than among women. ${ }^{20}$ Psoriasis is associated with limitations in daily activities, work, and sexual function. All of these factors negatively affect the patients' quality of life. ${ }^{21}$

Patients with psoriasis are prone to negative emotions, such as fear, dissatisfaction, anger, guilt and mental strain. Chronic stress and the lack of effective self-picture additionally cause social rejection which also exacerbate the psoriatic symptoms. Psoriasis might also have an effect on the patients interpersonal relations, both personal and professsional. Psoriasis cause a change in skin appearance which might also additionally purpose disgrace and embarrassment, causing the patients to withdrawal from interpersonal contacts. Some people even consider that psoriasis is contagious. Psoriasis also have a poor impact on professional and financial aspects, and additionally on their potential to work. Patients quality of life in professional and financial aspects depend on the cost of treatment, and the number of days they had off work. According to British data, almost $60 \%$ of patients are on sick leave for 26 days of a year. Notably, a few sufferers with psoriasis cannot do their jobs because of the change in their skin. An alarming rate, $80 \%$ of patients have issues with pariticipating in interpersonal relations at work. ${ }^{22}$

This research has some advantages, for instance increasing awareness of specific risk factors as the origins of psoriasis disease. Through identifying patient's quality of life, holistic treatment, which includes patient's quality life and patient's psychologic side, should also be considered in addition to medical treatment. However, this study has its limitation, i.e. lack of research subjects. It is because of the frequent findings of control patients who were respondents in our study before. As a suggestion for future research, longer period and larger sample size are needed to strengthen research potency. In addition, carrying out a DLQI assessment of psoriasis patients should also be conducted. It is because the majority of patients suffered from impaired quality of life. It is recommended to follow up consultations in other related fields of science.

In conclusion, the characteristics of the risk factors for psoriasis patients are trauma, sunlight, smoking, alcohol and infection. In symptoms and feelings aspects, most patients scored 6, which means significant effect. In daily activities aspects, most patients scored 0 , which means no effect at all. In activities in leisure time aspects, most patients scored 2, which means small effect. In work and school aspects, most patients scored 0 or no effect at all. In personal relationship aspects, most patients scored 0 or did not affect at all. Finally, in therapy aspects, most patients scored 0, which means no effect. Based on the interpretation of the Dermatology Life Quality Index score, most patients scored higher, which means significant effect to their quality of life. 


\section{REFERENCESS}

1. Gayatri L, Ervianti E. Studi retrospektif: psoriasis pustulosa generalisata. Berkala Ilmu Kesehatan Kulit dan Kelamin 2014; 26(1): 1-8.

2. Sticherling M. Psoriasis and autoimmunity. Autoimmunity reviews $2016 ; 15(12): 1167-70$.

3 . World Health Organization. Global report on psoriasis. Geneva: WHO Press; 2016. p. 11-2

4. Pratiwi KD, Damayanti D. Profil psoriasis vulgaris di RSUD Dr. Soetomo Surabaya: studi retropektif. Berkala Ilmu Kesehatan Kulit dan Kelamin 2018; 30(3): 248-54.

5. Burden A. D, Kirby B. Psoriasis and related disorders. In: Griffiths C, Barker, Bleiker T, Chalmers R, Creamer D, Editors. Rook's Textbook of Dermatology. 9th ed. Oxford: Wiley Blackwell; 2016. p. $35.4-5$

6. Rahmatina. Uji validitas dan reliabilitas dermatology life quality index (DLQI) berbahasa indonesia pada pasien poliklinik ilmu kesehatan kulit dan kelamin rumah sakit dr. Cipto Mangunkusumo. Jakarta: Universitas Indonesia 2013: 58-9

7. Kris MV, Adiguna MS, Wardhana M. Sindrom metabolik merupakan faktor risiko terjadinya psoriasis. Medicina. 2019; 50(2): 421-4.

8. Böhm D, Stock Gissendanner S, Bangemann K, Snitjer I, Werfel T, Weyergraf A, et al. Perceived relationships between severity of psoriasis symptoms, gender, stigmatization and quality of life. J Eur Acad Dermatol Venereol 2013; 27(2): 220-6.

9. Camargo, CM dos S, Brotas AM, Ramos-e-Silva M, Carneiro S. Isomorphic phenomenon of Koebner: facts and controversies. Clin Dermatol 2013; 31(6): 741-9.

10. Balato N, Di Costanzo L, Patruno C, Patrì A, Ayala F. Effect of weather and environmental factors on the clinical course of psoriasis. Occup Environ Med 2013; 70(8): 600

11. Li W, Han J, Choi HK, Qureshi AA. Smoking and risk of incident psoriasis among women and men in the United States: a combined analysis. Am J
Epidemiol 2012; 175(5): 402-13.

12. Lee EJ, Do Han K, Han JH, Lee JH. Smoking and risk of psoriasis: a nationwide cohort study. J Am Acad Dermatol 2017; 77(3): 573-5.

13. Svanström C. Lonne-Rahm SB, Nordlind K. Psoriasis and alcohol. Psoriasis: targets and therapy. Dove Med Press 2019; 9: 75-8.

14. Ko HC, Jwa SW, Song M, Kim MB, Kwon KS. Clinical course of guttate psoriasis: long-term follow-up study. J Dermatol 2010; 37(10): 894-9.

15. Dalmády S, Kemény L, Antal M, Gyulai R. Periodontitis: a newly identified comorbidity in psorisis and psoriatic arthritis. Expert Rev Clin Immunol 2020; 16(1): 101-8.

16. Yu-Su N, Yang Huang J, Jen Hu C, Chieh Yu H, Chao Chang Y. Increased risk of periodontitis in patients with psoriatic disease: a nationwide population-based retrospective cohort study. PMC 2017; 5-13.

17. Duarte GV, Follador I, Cavalheiro CM, Silva TS, de Oliveira MD. Psoriasis and obesity: literature review and recommendations for management. An Bras Dermatol 2010; 85(3): 355-60.

18. Mitchell H. Vaginal discharge - causes, diagnosis, and treatment. Br Med J 2004; 328(7451): 1306-8.

19. Armstrong AW, Bukhalo M, Blauvelt A. A clinician's guide to the diagnosis and treatment of candidiasis in patients with psoriasis. Am J Clin Dermatol 2016; 17(4): 329-36.

20. Kowalewska B, Cybulski M, Jankowiak B, Krajewska-Kułak E. Acceptance of illness, satisfaction with life, sense of stigmatization, and quality of life among people with psoriasis: a crossectional study. Dermatol Ther (Heidelb) 2020; 10: 41330 .

21. Bhosle MJ, Amit K, Steven RD, Rajesh B. Quality of life in patients with psoriasis. BioMed Central 2006; 4(35): 1-6

22. Owczarek K, Jaworski M. Quality of life and severity of skin changes in the dynamics of psoriasis. Postepy Dermatol Alergol 2016; 33(2):102-8. 